\title{
Muscular Dystrophy-Dystroglycanopathy (Limb-Girdle) Type C, 5
}

National Cancer Institute

\section{Source}

National Cancer Institute. Muscular Dystrophy-Dystroglycanopathy (Limb-Girdle) Type C,

5. NCl Thesaurus. Code C126739.

An autosomal recessive inherited limb-girdle muscular dystrophy caused by mutations in the gene encoding fukutin-related protein (FKRP). It is characterized by variable age at onset, normal cognition, and no structural brain changes. 